\title{
EDUCAÇÃO INFANTIL, INCLUSÃO E A TECNOLOGIA ASSISTIVA
}

\section{ARTIGO ORIGINAL}

FLORENTINO, Priscila Elaine ${ }^{1}$

LOPES, Sandra Aparecida ${ }^{2}$

FLORENTINO, Priscila Elaine. LOPES, Sandra Aparecida. Educação infantil, inclusão e a tecnologia assistiva. Revista Científica Multidisciplinar Núcleo do Conhecimento. Ano 05, Ed. 06, Vol. 13, pp. 93-106. Junho de 2020. ISSN: 2448-0959, Link de acesso: https://www.nucleodoconhecimento.com.br/educacao/inclusao-e-atecnologia

\section{RESUMO}

O presente artigo visa investigar a respeito da importância da tecnologia assistiva para o desenvolvimento da educação da pessoa com deficiência, realizando um levantamento bibliográfico sobre a relação que a educação infantil tem com educação especial e inclusiva, sua trajetória e avanços no Brasil. A inclusão na Educação Infantil segue devido o reconhecimento da criança pequena como sujeito de direitos, protagonista de sua propria história. Aos poucos a criança pequena passa a ter papel social, direitos de aprendizagem e desenvolvimento. Como metodologia utilizou-se de pesquisa bibliográfica a autores como Delgado Garcia (2017), Bersch (2017), Galvão Filho (2013), entre outros, que escreveram em livros, revistas, jornais, etc. sobre a Educação Especial aliada a Educação Infantil e a importância da capacitação de seus professores, como forma de melhor atender a criança pequena e auxiliar em seu desenvolvimento integral. Portanto essa pesquisa espera auxiliar futuros leitores sobre a importância da Educação Especial ser utilizada dentro da Educação Infantil.

\footnotetext{
${ }^{1}$ Especialista em Educação Infantil pela Escola Superior Aberta do Brasil (ESAB).

${ }^{2}$ Especialista em Psicopedagogia pela Faculdade Educacional da Lapa ( FAEL).
} 
Palavras-Chave: Educação Especial, tecnologia assistiva, desenvolvimento.

\section{INTRODUÇÃO}

No Brasil muito se fala sobre a educação especial, já que está se destina ao ensino de crianças com necessidades educacionais especiais. Esse campo da aprendizagem engloba os indivíduos com deficiência física, intelectual ou múltipla, características altas habilidades, superdotação ou talento entre muitas outras.

Varias mudanças sociais em relação a valorização da criança motivaram investimentos em saúde e educação, criando instituições de atendimento para a pessoa com deficiência. Prevalecia o ensino da autonomia, da capacitação da criança para se tornar independente, do fazer por si só, ou seja, o assistencialismo aliado a teorias e práticas educacionais de estimulação. Dessa forma essas instituições tinham o objetivo de desenvolver a pessoa com deficiência para conviver em sociedade.

Para a pessoa com deficiente eram criados recursos e métodos que serviam de apoio ao seu desenvolvimento conforme as suas necessidades especificas. Atualmente devido as crescentes novas tecnologias e a necessidade da inclusão dos indivíduos com qualquer deficiência, tem aumentado a pesquisa e o uso de recursos tecnológicos para auxiliar o desenvolvimento da pessoa com deficiência, denominada de tecnologia assistiva.

Portanto o artigo irá pesquisar sobre a importância da tecnologia assistiva ou tecnologia adaptativa, para o desenvolvimento da educação da pessoa ou criança com deficiência. Para isto utilizou-se de pesquisa bibliográfica a autores que escreveram sobre o assunto em livros, revistas, jornais, sites, entre outros, pontuando um breve relato sobre a educação infantil, educação especial e inclusiva, e a tecnologia assistiva e sua trajetória e avanços no Brasil.

\section{INCLUSÃO NA EDUCAÇÃO INFANTIL}

A vida educacional de uma pessoa começa na infância, desta forma se inicia quando a criança entra na educação infantil, que esta ganhando espaço dia após dia na 
sociedade. Desta forma todas as crianças independentes de suas necessidades têm o direito de estar inclusas na educação infantil. A constituição federal (BRASIL, 1988), em seu artigo 205, ressalta as obrigações que o Estado e a família tem a respeito de fornecer e providenciar instrução necessária para que o cidadão possa viver em sociedade, ou seja, essas obrigações devem ser cumpridas independente de ser uma pessoa com deficiência ou não.

As instituições de educação infantil têm o objetivo de oferecer uma educação de qualidade, para todas as crianças, sem discriminar nenhuma criança. Tendo necessidades especiais ou não, as mesma podem frequentar as instituições de ensino, tendo a oportunidade de se desenvolver, como as demais. O Referencial Curricular Nacional para Educação Infantil (BRASIL, 1998, p. 36), afirma que "o principal desafio da Escola Inclusiva é desenvolver uma Pedagogia centrada na criança, capaz de educar a todas, sem discriminação, respeitando suas diferenças". Para isto a instituição educacional que atende a criança deve oferecer educação de qualidade, investindo em equipamentos e profissionais capacitados para desenvolver o educando integralmente.

De acordo com Drago (2011) o atendimento formal deve dispor condições, para desenvolver e ampliar a aprendizagem da criança na Educação Infantil ou qualquer etapa educacional, independente de classe social, econômica ou politica, permitindo que a mesma cresça para além de seu meio social. Uma instituição de ensino não pode se negar a matricular e a incluir uma criança portadora de necessidades especiais, por que ao se recusar, a mesma estará infringindo a lei, ao negar acesso à educação, para uma pessoa portadora de necessidades especial.

$\mathrm{Na}$ inclusão o educador, deve ser pesquisador, a fim de aprimorar cada dia mais seu pratica pedagógica, para que possa atender as especificidades de cada aluno. Pois cada educando é diferente um do outro, e desta forma apresentam diferentes necessidades educacionais. A lei 13.146/15, de 6 de julho do ano de 2015, em seu artigo 27, ressalta que a educação deve ser para todos, mesmo aqueles que possuem limitações devem receber instruções necessárias para cumprir seu papel como cidadão (BRASIL, 2015). 
Montoan (2007) considera todo o processo de inclusão um desafio, já que exige melhorias e adaptações tanto por parte da estrutura do local de atendimento, quanto na parte pratica pedagógica educacional da instituição de ensino na Educação Básica e Superior. Quando o educador é um educador pesquisador, ele ira pesquisar e descobrir novos recursos pedagógicos, e ira realizar intervenções para que possa atender a cada aluno, fazendo o mesmo superar suas barreiras. Desta forma quando o professor se dedica, a se reformular, rever seus conceitos e realizar formações continuadas, ele ira sentir mais segurança em sua pratica pedagógica, e fazendo com que os educandos também sintam segurança no mesmo.

Minetto (2008) afirma que conhecimentos sobre o tema inclusão se tornou essencial para sanar os medos e inseguranças a respeito do atendimento a pessoa com deficiência. O novo exige mudanças, alterações, novas reestruturações, alternativas de como atender o aluno que tem deficiência no ambiente educacional.

Quanto mais conhecimento o educador demonstrar ter sobre as necessidades especiais dos educandos, mais confiança ele ira ter dos mesmos e das famílias. Já que estarão seguros que seu ente querido esta sendo bem atendido. Vale ressaltar que um bom relacionamento entre família e professores se constrói devagar e aos poucos, a partir de mudanças e progressos que os educando demonstram em seu desenvolvimento e aprendizagem (SILVA, 2010).

\section{TECNOLOGIA ASSISTIVA, SUA IMPORTÂNCIA E O PROFESSOR}

\subsection{TECNOLOGIA ASSISTIVA}

A Tecnologia Assistiva (TA) surge nos Estados Unidos em 1988, como legislação que regulamenta a compra de materiais, para serem utilizados como recursos para o aprendizado, da pessoas com deficiência. Sua origem no Brasil vem da tradução da língua inglesa de 'Assistive Technology' para Tecnologia Assistiva na língua portuguesa (GARCIA, 2012). 
O atendimento educacional especializado para a pessoa com deficiências ajuda a atender os educandos da melhor forma possível, de acordo com suas condições e limitações de aprendizagem e desenvolvimento. Buscam métodos para compensar as deficiências físicas, cognitivas, sensoriais ou mentais, por meio de adaptações no espaço educacional. Visam desenvolver sua autonomia dentro e fora da instituição educacional, e investindo na melhora de qualidade de vida do individuo (BRASIL, 1999).

Cada pessoa estuda e aprende de uma forma singular. Isso porque somos diferentes uns dos outros, além disso vivemos em ambientes e interesses distintos. Alguns gostam mais da área de leitura e escrita, outros da matemática, e assim por diante (MADUREIRA, 2016, p.48).

Devido a crescente difusão de informações, as Tecnologias de Informação e Comunicação (TIC), influenciam cada vez mais as culturas e a sociedade. $\mathrm{Na}$ área da educação especial tornou-se aliada, um recurso muito favorável para auxiliar o desenvolvimento pedagógicos, sendo denominada de Tecnologias Assistivas (TA) (OTOME, 2012).

Uma das características singulares da TA reside propriamente em sua finalidade, isto é, na sua destinação para promover funcionalidade, autonomia, independência, qualidade de vida e inclusão social das pessoas com deficiência, pessoas com mobilidade reduzida e/ou pessoas idosas a partir de sua utilização direta e pessoal pelos indivíduos que dela necessitam. Trata-se de um aspecto distintivo em relação a outros tipos de tecnologias congêneres, usualmente referidas a suas especificidades temáticas ou setoriais (digital, eletrônica, mecânica, etc.) e/ou pelo uso indireto e/ou aplicação técnica por terceiros (tecnologias médicas de reabilitação, por exemplo) (DELGADO GARCIA, 2017, p.14).

Para adquirir novos conhecimentos, o ser humano precisa de estímulos ambientais e crescimento físico, ou maturação do corpo. A tecnologia assistiva surge para amparar 
e dispor condições para que a criança da educação especial possa acompanhar e auxiliar o desenvolvimento do educacional da criança. $O$ termo tecnologia assistiva (TA) teve origem a partir do momento em que as pessoas com deficiência começaram a frequentar o espaço educacional. Sua modalidade visa auxiliar em tarefas acadêmicas e de adequação ao espaço escolar. sendo considerado recursos e adaptações para desenvolver e apoiar a aprendizagem, de modo a amplia suas possibilidades, habilidades para uma vida com mais independência (BERSCH, 2017).

Galvão Filho (2013) afirma que a tecnologia assistiva não pode ser entendida apenas como recursos ou aparatos para mediar aprendizagem, mas deve se levar em consideração para que são utilizados. Sem conhecimentos específicos sobre esses materiais e sua utilidade, não tem como extrair o máximo de aproveitamento do uso de tais tecnologias ao atender a pessoa com deficiência. $O$ professor de apoio educacional deve sempre estar em constantes estudos para se aprimorar constantemente.

As tecnologias assistivas ou adaptativas, são todas as técnicas projetados ou equipamentos adaptados, que amplie a mobilidade com a intensão de proporcionar ou favorecer a autonomia pessoal ou total. Mas as tecnologias ou métodos criados visando a melhoria do trabalho profissional, e não da vida cotidiana da pessoa com deficiência, não podem ser consideradas tecnologias Assistiva, já que não visam melhorar a sua vida diária (BERSCH, 2017).

O espaço educacional deve visar buscar recursos, adaptações e modificações tanto física como temporal ou de comunicação para que a pessoa com deficiência seja incluído. Dessa forma instintivamente irá desenvolver as habilidades propostas no currículo regular, podendo acompanhar a turma com equidade (GUIJARRO, 1992).

Rogalski (2010) a instituição de educação deve receber e providenciar métodos para ensinar e educar a criança, sendo esta com deficiência ou não. Adaptar o espaço físico, tempo e acompanhamento educacional por professores especialistas, de forma a atender todas as necessidades e garantir qualidade os direitos de aprendizagem da criança. 
Existem vários aparatos, objetos, materiais e adequações que podem ser utilizadas para a facilitação da aprendizagem da pessoa com deficiência. A adequação de equipamentos, mobiliários e acessibilidade auxiliam no desenvolvimento da criança. A utilização da comunicação aumentativa e alternativa, facilita o dialogo das pessoas que apresentam dificuldades na fala e na escrita. Outra ferramenta utilizada na comunicação consiste na adequação dos materiais didático pedagógicos realizado pelo educador especialista (SHIRMER, 2007).

O Comitê de Ajudas Técnicas (CAT), aprovado no ano de 2006, estabelece que o termo tecnologia assistiva deve ser utilizado para definir a área do conhecimento e de característica interdisciplinar. Visa proporcionar a autonomia, independência, qualidade de vida e inclusão social utilizando metodologias e praticas especificas de acordo com a necessidade da pessoa com deficiência (BRASIL, 2009).

Sassaki (2002) dialoga sobre a importância de procurar incluir todas as pessoas, como forma para construir uma sociedade mais justa e tolerante com as dificuldades de seu próximo. Viver consiste em mais que respirar, tem haver com interações com o meio que vive, com as pessoas a sua volta, com o mundo em si. E uma sociedade so sera inclusiva se procurarmos constantemente o adaptar ao novo e incluir a pessoa diferente, procurando sanar suas dificuldades, torna-lo humano.

Portanto a tecnologia assistiva pode ser descrita como recursos e equipamentos ou serviços, que ajudam e auxiliam ampliando o desenvolvimento de habilidades funcionais de pessoas com deficiência, sejam físicas ou intelectuais. Promovem sua autonomia, independência e inclusão na sociedade. Para a Educação a tecnologia funciona como uma ponte que serve de acesso para o educador se achegar na criança. Sua importância esta no que tal recurso permite a pessoa com deficiência a fazer (SCHIRMER, 2007).

\subsection{AS CATEGORIAS DE TECNOLOGIAS ASSISTIVA}

Diversos distúrbios e deficiências de aprendizagem, podem interferir e influenciar o desenvolvimento educacional da criança quando não identificados, de forma negativa. 
A tecnologia facilita e aumenta seu potencial de aprendizagem, ajuda a compensar as limitações das deficiências, fornecem modelos alternativos para solucionar problemas possibilitando melhor qualidade de vida (SMITH, 2008).

As adaptações devem ser especificas para cada criança, já que as deficiências podem ser diferentes, e ajudar a superar diferentes problemas. Tecnologia assistivas podem ser recursos que são os equipamentos e os serviços transdisciplinar, composto por profissionais de diversas áreas, que fornecem apoio a pessoa com deficiência, para que esta consiga utilizar os equipamentos da tecnologia assistiva (RODRIGUES, 2019).

Tecnologias assistivas auxiliam as pessoas em seu ambiente, seja, doméstico, no trabalho, nas instituições de ensino e nas ruas, entre outros. Se dividem em grupos, conforme as necessidades do individuo, tais como assistências diária, comunicação, acessibilidade ao computador, construções especificadas e ambientes controlados, próteses e entre muitos outros. Desta forma qualquer serviço ou produto pode ser considerado como ajuda técnica. Já que visam melhorar e auxiliar as habilidades da pessoa com deficiência, proporcionando uma maior autonomia (PORTUGAL, 2007).

\subsection{A IMPORTÂNCIA DA FORMAÇÃO DO PROFESSOR EDUCADOR INCLUSIVO}

$\mathrm{Na}$ educação infantil, o serviço do professor deve atuar como indissociável cuidar e educar, já que para criança pequena os cuidados são tão importantes como a educação oferecida. A prática pedagógica deve estar permeada de situações de aprendizagem criadas com intencionalidade de desenvolver integralmente a criança, baseada em habilidades que já possui e as que ainda não foram adquiridas. Geralmente são os professores, os primeiros a notarem qualquer alteração no desenvolvimento e aprendizagem, por isso se torna tão importante uma formação adequada (CARVALHO, 2015).

A inclusão não se resume em ter a criança frequentando classe do ensino regular, sem lhe oferecer apoio e condições para se desenvolver juntamente com seus colegas 
com equidade. Para que o aluno possa aprender com qualidade, deve ser acompanhado por um professor apoio, que possa servir de ponte entro 0 conhecimento e a criança De acordo com as Diretrizes para a Formação de Professores da Educação Básica, o professor tem seu papel importante em se mostrar orientador e mediador de conhecimentos, para isto deve sempre ser incentivado a desempenhar o seu papel docente frente as novas concepções de mundo. Cada vez mais, novas tecnologias são criadas para apoiar o professor, durante sua caminhada como mediador de conhecimento (OTOME, 2012).

A criança ou adulto que tiver dificuldades com a linguagem, as tecnologias assistivas podem ser utilizadas como ferramenta de comunicação. Se suas dificuldades forem em relacionadas a andar e caminhar, pode-se providenciar próteses entre outros. Diminuindo as necessidade de precisar de auxilio e aumentando a sua liberdade e autonomia (SANTOS, 2017).

Diferentemente do processo de escolarização, a educação infantil prioriza as relações e vivências educativas, distanciando-se do estilo clássico de transmitir conteúdo. Diferentemente dos outros níveis de ensino, o currículo é traçado por projetos regados de conteúdo, porém praticados de forma lúdica e muito interativa. Promove experiências de diversas formas às crianças (MEDEIROS, 2015, p.18).

Devido as varias transformações sociais, politicas e econômicas que ocorreram na sociedade, a criança passou a ser reconhecida como sujeito de direitos aos quais devem ser respeitados pela sociedade. Independentemente de condição física, social ou econômica, devem receber educação de forma que favoreça o seu desenvolvimento e aprendizagem integral. O brincar, interagir, rolar, aprender, viver, sonhar, imaginar, pensar, estão presentes a todo tempo, como ferramenta a qual a criança desvenda o mundo e tudo que Ihe rodeia (BRASIL, 2006).

Para garantir o direito da criança a uma educação de qualidade e que ao mesmo tempo atenda as suas necessidades, deve se investir em formações continua de professores. Para isto todos cursos de capacitação para a Educação Especial e 
Inclusiva não deve ser limitada a docentes especialista, mas deve envolver a todos os participantes do processo educativo (MARCHESI, 2004).

A Base Nacional Comum Curricular (BNCC) de 2017, afirma que a criança pequena, que frequenta o espaço educacional tem direitos inquestionáveis de ter acesso a educação de qualidade. Que visam a desenvolver as competências e habilidades integralmente. A educação infantil se baseia em direitos de aprendizagem e cinco campos de experiencia, que objetivam o desenvolvimento de todas as suas capacidades, sem esquecer que a criança aprende experimentando e vivenciando o mundo. Praticas pedagógicas devem ser pautadas no lúdico e nas interações, no brincar e experienciar (BRASIL, 2017).

A interação durante o brincar caracteriza o cotidiano da infância, trazendo consigo muitas aprendizagens e potenciais para 0 desenvolvimento integral das crianças. Ao observar as interações e a brincadeira entre as crianças e delas com os adultos, é possível identificar, por exemplo, a expressão dos afetos, a mediação das frustrações, a resolução de conflitos e a regulação das emoções (BRASIL, 2017, p.37).

$\mathrm{Na}$ educação infantil, o professor propõe as situações de aprendizado relacionando objetivos de aprendizagem e estratégias pedagógicas, de forma planejada considerando as peculiaridades e especificidades de cada criança. A intencionalidade em suas atividades propostas, permite preparar boas aulas, na qual o educador favoreça o desenvolvimento a integração do aluno com deficiência na sua turma. Para garantir essa qualidade, o professor deve ser formado e licenciado em curso de ensino superior, aprovado pelo Ministério da Educação (MEC) (MIRANDA, 2012).

\section{CONCLUSÃO}

O mundo esta crescendo e cada vez mais o conhecimento é multiplicado, para se criar uma sociedade mais igualitária, deve-se investir em educação de qualidade. Observou-se que a inclusão educacional é de suma importância para o pleno 
desenvolvimento das pessoas portadoras de necessidades especiais, também mostrou como a inclusão pode mudar a vida destas pessoas influenciando e possibilitando uma maior autonomia. Ainda temos um longo caminho a percorrer para que a pessoa com deficiência possa ser incluída totalmente em nossa sociedade.

Já que durante muito tempo as mesmas não tinham o direito de estarem inclusas nas instituições de ensino, e após algum tempo conquistaram o direito de estarem inclusas. O espaço bem preparado, com profissionais competentes para atender a criança, respeitando as suas limitações, faz se necessário no ambiente educacional. Necessita-se de investimentos em equipamentos tecnológicos e formação especialista.

$\mathrm{Na}$ educação infantil a educação inclusiva e as tecnologias assistivas vem caminhando e se desenvolvendo, buscando oportunizar o melhor atendimento para a criança especial. Pode se ver também como as tecnologias assistiva é importante para o desenvolvimento educacional, pois vem facilitando a vida de todos. As pessoas tem a possibilidade de realizar tarefas e atividades com mais autonomia, que não conseguiriam realizar sem consensualizar as tecnologias assistivas.

\section{REFERÊNCIAS}

BERSCH, Rita. Introdução à Tecnologia Assistiva. Assistiva - Tecnologia e Educação. Porto Alegre, RS, 2017.

BRASIL. Decreto n. 3.298 de 20 de setembro de 1999.Disponível em: < http://www.planalto.gov.br/ccivil_03/decreto/d3298.htm>. Acesso em: 24/05/2020.

. Educação infantil : saberes e práticas da inclusão : dificuldades acentuadas de aprendizagem : deficiência múltipla, 4. ed. Brasília : MEC/SEE, 2006.

- Base Nacional Comum Curricular: Educação basica. Brasília:

MEC/Secretaria de Educação Básica, 2017. Disponivel em:< http://basenacionalcomum.mec.gov.br/images/BNCC_EI_EF_110518_versaofinal_sit e.pdf>. Acesso em: 6/06/2020. 
- Constituição Federal. Brasília: Senado Federal, 1988. Disponível em: <https://www2.senado.leg.br/bdsf/bitstream/handle/id/518231/CF88_Livro_EC91_20 16.pdf>. Acessado em 29/05/2020.

- Ministerio da Educaççao e do Desporto. Secretaria de Educação Fundamental. Referencial Curricular Nacional para Educação Infantil. BRASILIA, 1998. Disponivel em: <http://portal.mec.gov.br/seb/arquivos/pdf/rcnei_vol1.pdf>. Acessado em: 29/05/2020.

. LEI № 9.394, DE 20 DE DEZEMBRO DE 1996. Diário Oficial de20/12/96. Disponível em <https://brasil.mylex.net/legislacao/estatuto-pessoa-deficiencialei13146-art28_93579.html> acesso em :15/05/2020.

.LEl 13.146/15. Disponivel em:<> em: 29/05/2020.

- Subsecretaria Nacional de Promoção dos Direitos da Pessoa com Deficiência. Comitê de Ajudas Técnicas. Tecnologia Assistiva . - Brasília: CORDE, 2009. Disponivem em:< http://galvaofilho.net/livro-tecnologia-assistiva_CAT.pdf>. Acesso em: 10/05/2020.

CARVALHO, J. B. dos S. A importância da formação de professores na escola inclusiva: estudo de caso da escola classe $\mathrm{n} 64$ de Ceilandia SulBrasilia/DF.UNB/UAB? BRASILIA, 2015.

DELGADO GARCIA, J. C., GALVÃO FILHO, T. A.; ; SANTOS, M. C. D. ; ROBERTO, M. V. ; MENDES, V. ; RIBEIRO, D. F. B. . Pesquisa nacional de inovação em Tecnologia Assistiva III (PNITA III): principais resultados, análise e recomendações para as políticas públicas. São Paulo: ITS Brasil, 2017. Disponivel em: $<$ http://itsbrasil.org.br/wp-content/uploads/2018/12/Livro-Pesquisa-Nacional-deInovacao.pdf>. Acesso em:10/06/2020.

DRAGO, R. Uma fresta na janela: A educação inclusiva. In: Inclusão na educação infantil. Rio de Janeiro, Wak Editora, $2011 . \quad$ Disponivel: 
https://periodicos.fclar.unesp.br/rpge/article/viewFile/10170/7099. Acessado em : 29/04/ 2020.

GALVÃO FILHO, Teófilo Alves. A construção do conceito de Tecnologia Assitiva: alguns novos interrogantes e desafios. Revista FACED, Porto Alegre, v. 2, 2013. Disponivel em: <http://www.galvaofilho.net/TA_desafios.pdf>. Acesso em:04/06/2020.

GARCIA, Jesus Carlos Delgado; GALVÃO FILHO, Teofilo Alves. Pesquisa nacional de tecnologia assistiva. São Paulo: ITS Brasil/MCT-SECIS, 2012.

GUIJARRO, R.B. (Org.) Alumnos con necesidades educativas especiales y adaptaciones curriculares. Espanha: Ministerio de Educación y Ciencia, 1992.

MANTOAN, M. T. E. A Educação especial no Brasil: da exclusão à inclusão escolar. 2007. Disponivel: https://periodicos.fclar.unesp.br/rpge/article/viewFile/10170/7099. Acesso em: 29 mai. 2020.

MARCHESI, Álvaro. A Prática das escolas inclusivas. In: Desenvolvimento psicológico e educação: Transtornos de desenvolvimento e necessidades educativas especiais. Porto Alegre: EDITORA ARTEMED, 2004.

MEDEIROS, Thais Brito. A tecnologia provendo a Inclusão na Educação Intantil: um estudo de caso. Porto Alegre: EFRS, 2015. Disponivel em: $<$ https://www.lume.ufrgs.br/bitstream/handle/10183/139593/000990502.pdf?sequenc e=1 >. Acesso em 10/06/2020.

MINETTO, M. F. O currículo na educação inclusiva: entendendo esse desafio. $2^{\mathrm{a}}$ ed. Curitiba: IBPEX, 2008. Disponivel em: <http://www.opet.com.br/faculdade/revistapedagogia/pdf/n14/n14-artigo-1-O-PAPEL-DO-PROFESSOR-NA-EDUCACAOINCLUSIVA.pdf>. Acesso em: 01/04/2020.

MIRANDA, Theresinha Guimarães; FILHO, Teofilo Alves Galvão. O professor e a educação inclusiva: formação praticas e lugares. Salvador: EDUFBA, 2012. Disponivem em:< 
OMOTE, S.; GIROTO, C. R. M.; POKER, R. B. As tecnologias nas práticas pedagógicas inclusivas. Marília/SP: Cultura Acadêmica, 238 p., 2012.

PORTUGAL. Secretariado Nacional de Reabilitação e Integração da Pessoa com Deficiência, 2007.

Disponivel em: $<$ http://www.inf.ufes.br/ zegonc/material/Comp_Sociedade/ZEGONC_Tecnologias_ Assistivas_Livro_Introducao_TA.pd>. Acessado em: 01/04/2020.

RODRIGUES, Leandro. Tecnologia Assistiva: o que é e como usar na escola sem saber informática, 2019. Disponivel em: <https://institutoitard.com.br/tecnologiaassistiva-o-que-e-e-como-usar-na-escola-sem-saber-informatica/>. Acesso em: 20/05/2020.

ROGALSKI, Solange Menin. Histórico do surgimento da Educação Especial. Rei Revista de Educação do IDEAU, v.5, noำ 12, 2010.

SANTOS, Cristiane Sousa.; ALMEIDA, Yara de Souza. Inclusão na educação infantil: desafios e possibilidades através das práticas pedagógicas. Revista on line de Política e Gestão Educacional, Araraquara, v.21, n.3, p. 1423-1432, set./dez. 2017.

SASSAKI, Romeu Kazumi. Inclusão: construindo uma sociedade para todos. 4 ed. Rio de Janeiro: WVA, 2002.

SCHIRMER, Carolina R. ET al. Atendimento Educacional Especializado. Formação Continuada a Distância de Professores para o Atendimento Educacional Especializado, Deficiência Física, SEESP / SEED / MEC Brasília/DF, 2007. Disponivel em:< http://portal.mec.gov.br/seesp/arquivos/pdf/aee_df.pdf>. Acesso em: 23 mai. 2020.

SILVA, A. M. Educação especial e inclusão escolar: história e fundamentos. Curitiba: IBPEX, (Série Inclusão Escolar). p. 215, 2010. Disponivel em: $<$ http://www.opet.com.br/faculdade/revista-pedagogia/pdf/n14/n14-artigo-1-OPAPEL-DO-PROFESSOR-NA-EDUCACAO-INCLUSIVA.pdf>. Acessado em: 01/04/2020. 
SMITH, DeborH Deutscki. Introdução a Educação especial: ensinar em tempos de inclusão. $5^{\circ}$ ed. Porto Alegre: Artmed, 2008.

Enviado: Junho, 2020.

Aprovado: Junho, 2020. 